\title{
Identifying the Most Effective Model for Understanding the Growth Rate of Government e-Transactions: Brown's Model of Exponential Smoothing
}

\author{
Abhishek Roy, Gautam Dutta and Prabir Kumar Das \\ Indian Institute of Foreign Trade, Kolkata Campus, West Bengal, India \\ E-Mail: abhishekroy.dit@gmail.com, gautam@iift.edu,pkdas@iift.edu
}

\begin{abstract}
The purpose of this study is to investigate the current status of e-transactions time series growth rate in the state of Jharkhand from January 2013 to 20th May, 2018 to understand the citizen adoption pattern of various egovernment services. Government spends lots of money in developing and implementing e-services, but despite spending huge money the adoption rate is low. This study will analyze the adoption rate by using time series models and find the adoption pattern to improve the future adoption rate of eservices. Besides this, the paper will help us to understand whether current e-transaction methods are user friendly or not. Therefore, identify the best model to evaluate the growth rate of e-transactions in the context of government electronic transactions. In this regard, various existing time series models have been evaluated to obtain the result of this study. The paper draws-up the emergent model derived from the analysis. Finally, a framework is suggested to select Brown's Exponential Smoothing Model as an ideal model for evaluating the growth rate of government e-transaction for the state of Jharkhand. This will help government to recommend and strategize better e-services plan for the state. This research can be used in policy making, strategizing and finding the key to user acceptance of innovation in technology in government electronic transaction with the help of Brown's Exponential Smoothing as it can reduce the impacts of seasonal factors.

Keywords: Government e-services, e-transaction, time series, exponential smoothing, Brown's model, Brown's double exponential smoothing, growth rate, diffusion, e-Governance
\end{abstract}

\section{INTRODUCTION}

Jharkhand Government has implemented various eGovernment projects to make the government services easier, speedier and more approachable for people. It can happen a little late or it can be said that the state has understood the advantages of implementing the new service procedures little later than the other states, however, Jharkhand has attained a good review on the projects of their e-Governance department. The Government of India has launched the new system through which the government can serve the citizens individually (Barua, 2012).The main motto of this new implementation was to shift the focus to the citizens' requirements as well as to develop the government portals from the point of view of the citizens in the country. Like other states Jharkhand has also implemented these e-Governance services in their state. JAP-IT is the Nodal Agency for implementing the eGovernance activities in Jharkhand and it delivers more than 100 citizen-centric services in the state. As per the research of Barua, 2012, in Jharkhand the e-Governance system is depending on the three pillars of SWAN, SDC, and CSC. These three projects had taken the responsibility to make the state government services easier, smoother and time saving.

In North America, almost $90 \%$ of online retail transactions were made with this payment type (Ndou, 2004). However, the use of credit card or any other smartcard needs security measures to overcome the threat of hacking. The countries like China, India has some problems to overcome in regard to security (Ndou, 2004).

The research will allow analyzing the effectiveness of existing time series models for defining the growth rate of government e-transactions and discuss the limitations of the existing models and theories to understand and analyze the issues related to the acceptance of government e-transaction in the State of Jharkhand. Therefore, the objectives of the research are:

1. To understand the adaption pattern of e-Governance services in the State of Jharkhand in India

2. To propose a model for analyzing the growth pattern of government e-transactions in the state of Jharkhand

3 . To evaluate the future potentiality of these government eTransactions in the State of Jharkhand in India

\section{LITERATURE REVIEW}

Usually, the literature review section is related to analysis various previous theories and models for giving evidence of the research topic. Although there are a number of researches on e-commerce or banking, however, there are no such researches on governments, e-Transactions. Therefore, Time Series, Brown's Exponential Smoothing Models and many existing applications regarding this has been evaluated and then a model is suggested in order to suggest the best model suited for understanding the growth rate of Jharkhand's e-transactions.

As the number of researches on government's e-transaction is very low, therefore, the study has evaluated the data gained from a few pieces of research on developing countries e-Governance policies. In the developing countries like China, India, e-Governance has not yet reached the masses (Ndou, 2004).According to "ComputerBased Forecasting In Managing Risks Associated With 
Electronic Banking In Nigeria" paper, the results showed an easier and better way of analyzing and managing electronic banking risks in Nigeria reducing the risk factors of electronic banking. According to the study of " Evaluating The Developmental Impact of e-Governance Initiatives: An Exploratory Framework", the impact of two new implementations of FRIENDS and AKSHAYA egovernance projects in the southern state of Kerala has been evaluated. Like many other developing countries, India has taken great steps in implementing e-governance applications in recent years.

In the paper named, "Citizen-centric e-government performance: satisfaction with e-information", the citizencentric government systems of China has been discussed to evaluate the reaction of people of that country. It shows that the people of the country were very happy and helpful to use the e-information and e-Governance services (Chen and Zhang, 2012). The paper " Responding to information needs of the citizens through e-government portals and online services in India " has focused on National Portal of India, which provides single window access to 601 e-government portals and websites in India and evaluated digitization of documents, acts, rules and schemes of central and state government departments and their availability and accessibility through government portals. In Nigeria, the risks and challenges faced in the electronic banking system have been discussed in " Computer-Based Forecasting In Managing Risks Associated With Electronic Banking In Nigeria " by Onu, (2017). Hirwade, (2010) has researched about the existing government portals in India and evaluated the advantages as well as disadvantages of these. The study has revealed that the delivery of online services through government portals is an evolutionary phenomenon, and requires a change in the mindset of one and all e citizens, executives and the government in a developing country like India. With the support of the Internet, government processes can be made efficient, effective, and citizenfriendly.

\section{A. Theories}

\section{Time Series}

A time series is a grouping of observations which are requested in time. A model of the arrangement that clarified the past qualities may likewise anticipate whether and how much the next couple of qualities will increment or decline and this is the foremost purpose of this Time Series as it examines and analyses the future figure estimations of the arrangement. Time series analysis can be performed over both columns based and multidimensional data.

\section{Exponential Smoothing}

In 1950's the definition of exponential smoothing forecasting techniques has become known from the first work of Brown (1959, 1962) and Holt (1960) who were working on constructing deterministic models for stock control frameworks. Every sample of data collected over time experiences from one or the other kind of random variation. There are different measures which are used for wiping out the impact of random variation in data. Random variation makes it difficult to predict the model fitting the data and also generates inconsistency during forecasting and predictive modeling. Smoothing is primarily utilized to help forecast trends. Two most popular smoothing techniques used are Moving Averages and Exponential Smoothing.

\section{Brown's Model for Exponential Smoothing}

The brown's model is appropriate for series in which there are a linear trend and no seasonality (Brown and Meyer, 1961). Brown's model is, therefore, a special case of Holt's model. Brown's exponential smoothing is most similar to an ARIMA (Autoregressive Integrated Moving Averages) model with zero orders of auto regression, two orders of differencing, and two orders of moving average, with the coefficient for the second order of moving average equal to the square of one-half of the coefficient for the first order, which uses two different smoothed series that are centered at different points in time. The Brown's model for exponential smoothing is also known as Double Exponential Smoothing method. The forecasting formula is based on an extrapolation of a line through the two centers. Brown's forecasting method is similar to Simple Exponential Smoothing, except that the smoothing constant in Double Exponential Smoothing is derived by "re-smoothing" the single smoothed constant from Single Exponential Smoothing model. Exponential smoothing must be updated each period - level and trend.

\section{B. Characteristics of Brown's model}

Brown model should be used when the time series data has a trend but no seasonality. The latter occurs when the data exhibits rise and fall that are not for a fixed period. These fluctuations are usually due to economic conditions and are often related to the "business cycle." The period of time generally extends beyond a single year and the fluctuations are usually of at least two years. For detecting seasonality in absolute terms, that is whether seasonality is present or absent, even a detailed data observation can give results. The presence of seasonality can be confirmed by the presence of continuous spikes in various series plots like run sequence plot, seasonal subseries plot, multiple box plots and autocorrelation plot. Since the brown model is more suited for non-seasonal data, the fitting parameters are restricted to level and trend. However, the indices are defined for all the three parameters. At any given time, the level index gives an estimate of the local mean, or "level" of the data-generating process (DGP), at this time. The trend index gives an estimate of the trend at this time, and the seasonality index calculates approximately the digression from the local mean due to seasonality. Brown model make use of a level component and a trend component at every period. It uses two weights or smoothing parameters, to update the components at each period. 
In his original paper in 1961(Brown \& Meyer, 1961), R.G brown asserted that given a time series $\{\mathrm{Xt}\}$ with observations at equally spaced intervals, the first $\mathrm{N}+1$ degrees of exponential smoothing can be combined, using the binomial coefficients, to give an estimate of the values of the coefficients of an Nth degree polynomial model of the observations to date, evaluated at the time of the most recent observation. Brown also states that if the sample interval is short, there will be a large annual cost of doing the computations. Also if the sampling interval is too large, then a change in the data pattern will not be reflected quickly in the computations. Hence a medium-sized sample is most suited for Brown's model. Brown's selection of the sample interval also takes into consideration a) the cost of the data processing $b$ ) the cost of being late in recognizing a change c) the probability distribution of changes, by magnitude and time. Garcia (García et al., 2016) compares three different methods for multi-step forecasting of chlorine decay including the Brown's method, in an attempt to diagnose the quality sensors in the Barcelona drinking water network. In this study, the brown model is found to be performing relatively better in estimating the $\mathrm{PH}$ of the water, which is an important determinant of remaining useful life (RUL) of a water body. The absence of seasonality in the data for water bodies is an important reason why Brown model performs significantly better than the other models. Hansun (Hansun and Subanar, 2016) introduces a new approach to Brown's Double Exponential Smoothing in time series analysis. The new approach combines the calculation of weighting factor in Weighted Moving Average and implements the results with Brown's Double Exponential Smoothing method. The proposed method is tested on Jakarta Stock Exchange (JKSE) composite index, for which the data has a trend but is devoid of seasonality. Kumari (Kumari et al., 2014) compares the forecasting ability of different statistical models for the productivity of rice in India. Brown's method uses only one smoothing constant and that the estimated trend values are very sensitive to random influences. Saputra (Saputra, 2016) uses Brown's and Holt's Double Exponential Smoothing for predicting Indonesian Crude Oil Price (ICP). Asadi (Al-Asadi et al., 2017) attempts the forecasting of the number of brick production using the exponential smoothing holt-winter method which is similar to the Brown model except for the fact that the Mean Squared Error (MSE) is relatively smaller compared to the Brown model. Fomby (Fomby, 2008) states that exponential smoothing methods suffer from not having an objective statistical identification and diagnostic system for evaluating the goodness of competing exponential smoothing models.

\section{Importance of Seasonality Prediction}

In time series data, Seasonality is the presence of variations that occur at specific regular intervals less than a year, such as weekly, monthly, or quarterly. Seasonality may be caused by various factors, such as weather, vacation, and holidays and consists of periodic, repetitive, and generally regular and predictable patterns in the levels of a time series (Nazim and Afthanorhan, 2014). Therefore, it is a very important factor that can impact the e-transaction applications. In order to get this seasonality effect properly Brown's Model for Exponential Smoothing is accepted in this case as the only model that can identify the seasonality prediction.

\section{METHODOLOGY}

In order to conduct this research, the complete view of what are the factors related to e-transactions, a literature review of selected papers has discussed. Brown's model, Brown's double exponential smoothing. The literature review used a meta-analysis approach so as to understand the ways of evaluating the rate of e-transaction in the systems of online payment or transactions. The previous studies have helped in this analysis process to identify the appropriate model that can give a smooth and fast way to calculate the etransaction rate. The articles published in the journals were coded for capturing the publication year, keywords, topics, concepts, variables, theories and models and methodologies used. The keywords were taken as is given by the authors and also captured from the main text of the articles since the details of the concepts, variables, frameworks; theories explain the research in totality. This way valuable detail of each paper was captured. Those that were not found suitable for the context of this study were rejected. For surveys, they have used online questionnaires, postal questionnaires and telephonic surveys.

The data has been acquired from the portal e-Taal, which is a portal developed by India's National Informatics Centre to measure the impact of various e-governance initiatives at national and state levels. e-Taal provides a real-time view of e-transactions taking place under various e-Governance applications implemented by Government, on the basis of transaction count shared by them in an automated manner using Web Services technology. Real time utilization status and consolidated e-Transaction statistics of e-Governance Projects across India can be viewed on e-Taal. etransactions data for the state of Jharkhand has been downloaded from e-Taal for this study.

\section{FINDING AND ANALYSIS}

\section{A. Data description and results}

The e-transaction data for the State of Jharkhand downloaded from e-Taal from 1st January 2013 to 20th May 2018. The downloaded data was aligned and defined as time series daily data in SPSS. This data is daily and consists of 1977 data points from 1/01/2013 to 20/05/2018

\section{B. SPSS Time Series Model details}

Normalized BIC - Normalized Bayesian Information Criterion. A general measure of the overall fit of a model that attempts to account for model complexity. 
TABLE I MODEL SUMMARY RESULT OF SPSS

\begin{tabular}{|l|c|c|c|c|c|}
\hline \multicolumn{1}{|c|}{ Fit Statistic } & Mean & SE & Minimum & Maximum & Percentile \\
\hline Stationary R-squared & .832 &. & .832 & .832 & .832 \\
\hline R-squared & .013 &. & .013 & .013 & .013 \\
\hline RMSE & 106008.506 &. & 106008.506 & 106008.506 & 106008.506 \\
\hline MAPE & 109.411 &. & 109.411 & 109.411 & 109.411 \\
\hline MaxAPE & 2415.087 &. & 2415.087 & 2415.087 & 2415.087 \\
\hline MAE & 25270.637 &. & 25270.637 & 25270.637 & 25270.637 \\
\hline MaxAE & 2663668.131 &. & 2663668.131 & 2663668.131 & 2663668.131 \\
\hline Normalized BIC & 23.146 &. & 23.146 & 23.146 & 23.146 \\
\hline
\end{tabular}

$R$-squared: It is the proportion of variation in the dependent variable explained by the regression model. It ranges in value from 0 to 1 .

Stationary R-squared: A measure that compares the stationary part of the model to a simple mean model. Positive values mean that the model under consideration is better than the baseline model.

RMSE: Root Mean Squared Error measures the average magnitude of errors in a quadratic scoring rule.
$M A E$ - This is one of the measurement processes for forecasting time series, where the average magnitude of the errors in a set of predictions, without considering their direction.

MAPE - Mean Absolute Percentage Error is used to measure prediction accuracy of forecasting method in statistics. It uses percentage as the medium of expressing accuracy.

MaxAe - Maximum Absolute Error. The largest forecasted error expressed in the same units as the dependent series.

TABLE II MOdEL STATISTICS

\begin{tabular}{|c|c|c|c|c|c|}
\hline \multicolumn{5}{|c|}{ Model Statistics } \\
\hline \multirow{2}{*}{ Model } & \multirow{2}{*}{ Number of Predictors } & Model Fit statistics & \multicolumn{3}{|c|}{ Ljung-Box Q(18) } \\
\cline { 3 - 6 } & & Stationary R-squared & Statistics & DF & Sig. \\
\hline Jharkhand-Model_1 & 0 & .832 & 7.048 & 17 & .983 \\
\hline
\end{tabular}

Next, we have a look at the model statistics obtained from SPSS. Looking at the Ljung-Box Q test, we find that the value of $\mathrm{Q}$ statistic for the test comes out to be 7.048 corresponding to 17 degrees of freedom. However, the test is found to be significant only at level 0.983 which leads to the conclusion that the data is not independently distributed and it exhibits serial correlation.

\section{Selection of Best Time Series model on the basis of $M A P E$ and BIC values}

We can also have a look at the Mean Absolute Percentage Error and Bayesian Information Criterion statistics to determine the best fitting model for our data and for estimation purposes. Since the mean absolute percentage error is a measure of deviation, it is perfect as a measure of prediction accuracy of a forecasting method in statistics, for example in trend estimation. On the other hand, Bayesian Information Criterion (BIC) is a model selection tool. If a model is estimated on a particular data set (training set), BIC score gives an estimate of the model performance on a new, fresh data set (testing set). BIC is given by the formula:

BIC $=-2 * \log$ likelihood $+\mathrm{d} * \log (\mathrm{N})$,

where $\mathrm{N}$ is the sample size of the training set and $\mathrm{d}$ is the total number of parameters. The lower BIC score signals a better model. BIC attempts to mitigate the risk of over- fitting by introducing the penalty term $d * \log (\mathrm{N})$, which grows with the number of parameters. This permits filtering out of pointlessly complex models, which have too many parameters to be anticipated accurately on a given data set of size N. We can use the combination of these 2 parameters for selecting the best model for our data. The statistical software that we use for calculating these 2 values for different pre-defined models is IBM SPSS. IBM SPSS includes Simple, Simple Seasonal, Holt's Linear Trend, Brown's Linear Trend, Damped Trend, Winters' Additive, and Winters' Multiplicative in the Time-Series modeling procedure within its Statistics and Modeler statistical packages. The expert modeler function of IBM SPSS works in a similar manner, that is, it compares the MAPE and BIC values for determining the best model for a dataset. We will now have a look at the different models and the MAPE and BIC values for each of them for selection of the best model through comparative analysis.

Brown's linear trend- This model is appropriate for series in which there is a linear trend and no seasonality. Its smoothing parameters are level and trend, which are assumed to be equal. Brown's model is therefore a special case of Holt's model. A mathematically equivalent form of Brown's linear exponential smoothing model, which emphasizes its non-stationary character, is the following:

$$
\mathrm{Y}(\text { hat })_{\mathrm{t}}-\mathrm{Y}_{\mathrm{t}-1}=\mathrm{Y}_{\mathrm{t}-1}-\mathrm{Y}_{\mathrm{t}-2}-2(1-\alpha) \mathrm{e}_{\mathrm{t}-1}+\left((1-\alpha)^{\wedge} 2\right) \mathrm{e}_{\mathrm{t}-2}
$$


TABLE III MODEL DESCRIPTIONS

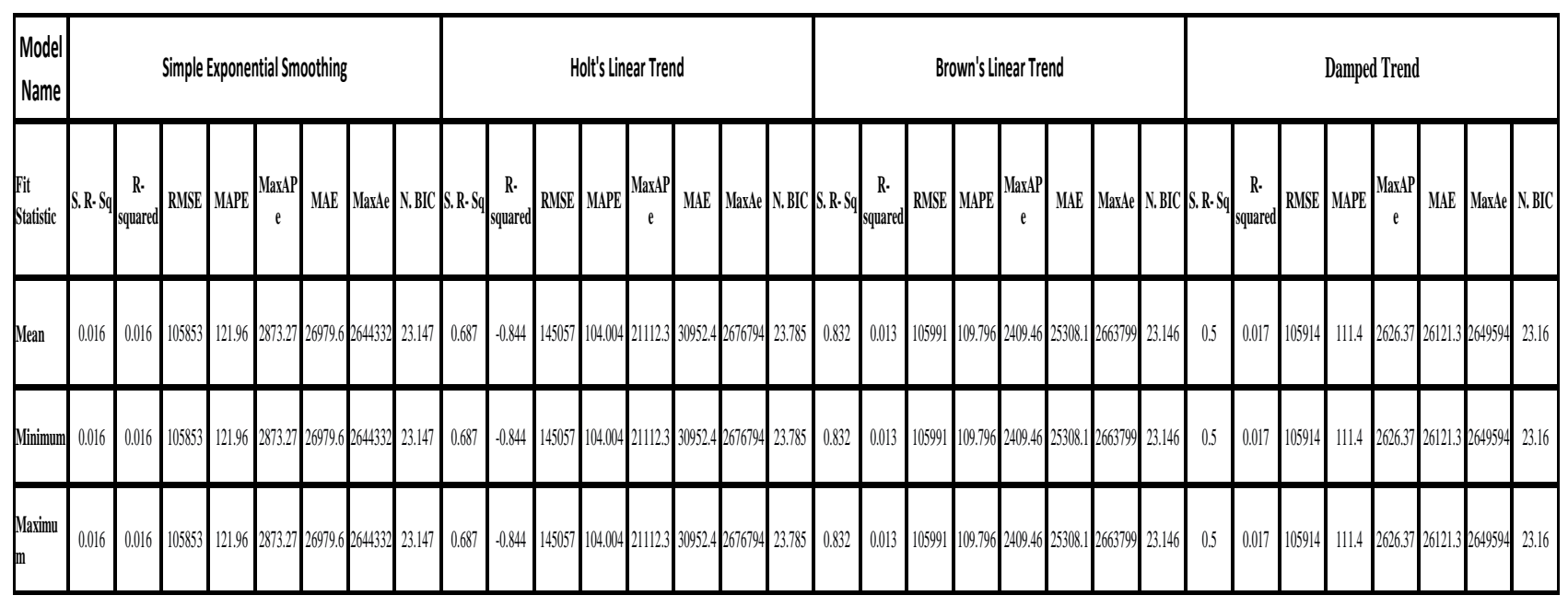

TABLE IV COMPARISON RESULT OF DIFFERENT MODELS

\begin{tabular}{|l|c|c|c|c|c|c|}
\hline \multicolumn{1}{|c|}{ Model Name } & MAPE & BIC & $\begin{array}{c}\text { Stationary } \\
\text { R Squared }\end{array}$ & RMSE & R Squared & $\begin{array}{c}\text { Mean Absolute } \\
\text { Error }\end{array}$ \\
\hline $\begin{array}{l}\text { Simple Exponential } \\
\text { Smoothing }\end{array}$ & 121.96 & 23.147 & 0.016 & 105853.3 & 0.016 & 26979.63 \\
\hline Holt's Linear & 104.004 & 23.785 & 0.687 & 145057.4 & -0.844 & 30952.42 \\
\hline Brown's Linear & 109.796 & 23.146 & 0.832 & 105990.7 & 0.013 & 25308.09 \\
\hline Damped Trend & 111.4 & 23.16 & 0.5 & 105913.8 & 0.017 & 26121.3 \\
\hline
\end{tabular}

Hence Brown Model is a good representation of the data set of the state of Jharkhand and is the best fitting model for forecasting through our data. Besides this, the value of MEA is also lowest for Brown model according to the analysis. Therefore, Brown model stands out to be the suitable forecasting model for Jharkhand.

\section{Limitation of this Study}

The study has been conducted with the data downloaded from the e-TAAL, which provides a real-time view of etransactions taking place under various e-Governance applications implemented by Government, on the basis of transaction count shared by them in an automated manner using Web Services technology. As such e-transaction data of only applications connected to the e-Taal portal has been captured \& analyzed in the study. Any e-Governance application/s of Jharkhand Government, not integrated to the e-Taal portal has not been captured and analyzed in this study, due to non-availability of the e-transactions data of such projects at a central level

\section{V.CONCLUSION}

To solidify the result obtained through theoretical analysis, we apply Time Series Modeler to the data sample in SPSS. Once again, the best fitting model is found to be Brown's model, hence reaffirming the result of our analysis. This study proves that any data with the presence of trend and the absence of seasonality can be analyzed through Brown's exponential smoothing since Brown model is usually the best fitting model and can be used to obtain relatively more accurate forecast results for the given data.

The diagram below shows the forecast result for $\mathrm{e}$ transactions data in Jharkhand, using Brown's model. As we can see in the diagram, the estimate obtained is linear, and indicates that the estimated number of e transactions would rise as the time period increases to 2177 .

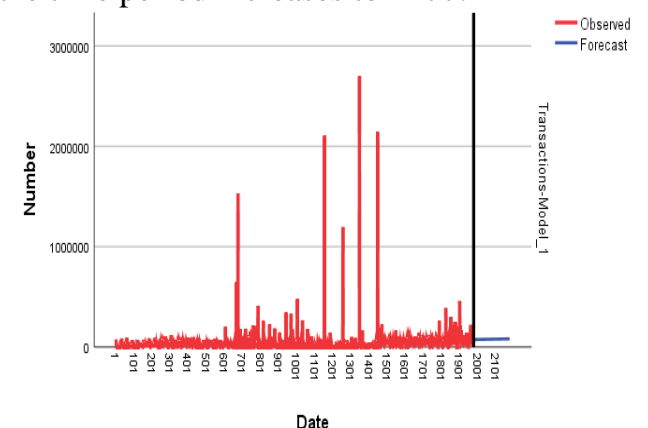

Fig. 1 forecast result for e transactions data in Jharkhand, using Brown's model

The future implications of this prediction are that the e transactions, in their present format, will continue to increase linearly. However, if we can come up with better ideas, designs and implementations for such e services in future, we can expect an exponential increase in the estimates for the same. Also if we are able to obtain the data for user base expectations and feedback regarding previous e services, we would be able to foster better development strategies and combine the data for user base with services analysis to come up with better quality of e services. 


\section{REFERENCES}

[1] A.N. Al-Asadi, et al., "Forecasting The Number Of Brick Production Using The Method Of Exponential Smoothing Holt-Winter (Case Study: PtSikKrian)". Journal of Electrical Engineering And Computer Sciences, Vol. 1,No. 2, 2017

[2] M. Barua, "E-governance adoption in government organization of India", International Journal of Managing Public Sector Information and Communication Technologies, Vol. 3, No. 1, pp.1, 2012

[3] R. G. Brown and R. F. Meyer, "The Fundamental Theorem of Exponential Smoothing", Operations Research, Vol. 9, No. 5, pp.673-685, 1961

[4] Y.C. Chen and J.C. Zhang, "Citizen-centric e-government performance: satisfaction with e-information", Electronic Government, An International Journal, Vol. 9, No. 4, pp.388-402, 2012

[5] C.Y. Chiang, W.T. Lin and N.C. Suresh, "An empirically-simulated investigation of the impact of demand forecasting on the bullwhip effect: Evidence from US auto industry", International Journal of Production Economics, Vol. 177, pp.53-65, 2016

[6] D.B. Crane and J.R. Crotty, "A two-stage forecasting model: Exponential smoothing and multiple regression", In Readings in Managerial Economics, pp.128-136, 1976

[7] D.A. D'Esopo, "A note on forecasting by the exponential smoothing operator", Operations Research, Vol. 9, No. 5, pp.686-687, 1961

[8] "Electronic Transaction Aggregation Analysis Layer". Internet: https://etaal.gov.in [May, 2018]

[9] P.G. Enns, et al., "Forecasting applications of an adaptive multiple exponential smoothing model", Management Science, Vol. 28, No. 9, pp.1035-1044, 1982

[10] T. B. Fomby, "Exponential smoothing models", Mannual SAS/ETS Software: Time Series Forecasting System, Vol. 6, pp.225-235, 2008

[11] D. García, et al., "Prognosis of quality sensors in the Barcelona drinking water network", Control and Fault-Tolerant Systems (SysTol), 3rd Conference, pp.446-451, 2016
[12] Govt. of Jharkhand, "Reform in Jharkhand through e-Governance", Jharkhand Agency for Promotion of Information Technology (JAPIT), May, 2015

[13] S. Madon, "Evaluating the developmental impact of e-governance initiatives: an exploratory framework", The Electronic Journal of Information Systems in Developing Countries, Vol. 20, No. 1, pp.113,2004

[14] T. Miller and M. Liberatore, "Seasonal exponential smoothing with damped trends: An application for production planning", International Journal of Forecasting, Vol. 9, No. 4, pp.509-515, 1993

[15] A. Nazim, and A. Afthanorhan, "A comparison between single exponential smoothing (SES), double exponential smoothing (DES), holt's (brown) and adaptive response rate exponential smoothing (ARRES) techniques in forecasting Malaysia population", Global Journal of Mathematical Analysis, Vol. 2, No. 4, pp.276-280, 2014

[16] V.D. Ndou, "E-Government for developing countries: opportunities and challenges", The electronic journal of information systems in developing countries, Vol. 18, No. 1, pp.1-24, 2004

[17] F.U. Onu, C.V. Umeakuka and S.E. Eneji,"Computer Based Forecasting In Managing Risks Associated With Electronic Banking In Nigeria", International Journal of Innovative Research and Advanced Studies (IJIRAS), Vol. 4, No. 3, 2017

[18] N.D. Saputra, A. Aziz and B. Harjito, "October. Parameter optimization of Brown's and Holt's double exponential smoothing using golden section method for predicting Indonesian Crude Oil Price (ICP)", Information Technology, Computer, and Electrical Engineering (ICITACEE), 2016 3rd International Conference on pp.356-360, 2016

[19] J. Wikner, "Analysis of smoothing techniques: application to production-inventory systems'", Kybernetes, Vol. 35, No. 9, pp.13231347,2006 